\title{
In-hospital mortality and successful weaning from venoarterial extracorporeal membrane oxygenation: analysis of 5,263 patients using a national inpatient database in Japan
}

\author{
Shotaro Aso ${ }^{1}$, Hiroki Matsui ${ }^{1}$, Kiyohide Fushimi ${ }^{2}$ and Hideo Yasunaga ${ }^{1 *}$
}

\begin{abstract}
Background: The mortality rate of severely ill patients treated with venoarterial extracorporeal membrane oxygenation (VA-ECMO) remains unknown because of differences in patient background, clinical settings, and sample sizes between studies. We determined the in-hospital mortality of VA-ECMO patients and the proportion weaned from VA-ECMO using a national inpatient database in Japan.
\end{abstract}

Methods: Patients aged $\geq 19$ years who received VA-ECMO during hospitalization for cardiogenic shock, pulmonary embolism, hypothermia, poisoning, or trauma between 1 July 2010 and 31 March 2013 were identified, using The Japanese Diagnosis Procedure Combination national inpatient database.

Results: The primary outcome was in-hospital mortality and the secondary outcome was the proportion weaned from VA-ECMO. A total of 5263 patients received VA-ECMO during the study period. The majority of patients had cardiogenic shock $(n=4,658)$. The number of patients weaned from VA-ECMO was $3389(64.4 \%)$ and in-hospital mortality after weaning from VA-ECMO was 1994 (37.9\%). In-hospital mortality without cardiac arrest in the cardiogenic shock group was significantly lower than that in patients with cardiac arrest $(70.5 \%$ vs. $77.1 \%, p<0.001)$. In the multivariable logistic regression including multiple imputation, higher age and greater or smaller body mass index were significantly associated with in-hospital mortality, whereas hospital volume was not associated with such mortality.

Conclusions: The present nationwide study showed high mortality rates in patients who received $V A-E C M O$, and in particular in patients with cardiogenic shock and in patients with cardiac arrest. Weaning from VA-ECMO did not necessarily result in survival. Further studies are warranted to clarify risk-adjusted mortality of VA-ECMO using more detailed data on patient background.

Keywords: Age factors, Cardiogenic shock, Extracorporeal membrane oxygenation, Cardiac arrest, Mortality

\footnotetext{
* Correspondence: yasunagah-tky@umin.ac.jp

${ }^{1}$ Department of Clinical Epidemiology and Health Economics, School of

Public Health, The University of Tokyo, 7-3-1 Hongo, Bunkyo-ku, Tokyo

113-0033, Japan

Full list of author information is available at the end of the article
} 


\section{Background}

Venoarterial extracorporeal membrane oxygenation (VA-ECMO) is one of the life-supporting procedures that may be given to critically ill patients with refractory cardiogenic shock, pulmonary embolism, hypothermia, or drug poisoning $[1,2]$. VA-ECMO can be used temporarily in critically ill patients until intensive therapies for underlying diseases take effect. Thus, VA-ECMO is considered to be a last resort to save life.

The reported mortality of patients with refractory cardiogenic shock treated with VA-ECMO varies widely (24-64 \%), and may be related to differences in patient background and clinical settings. Previous studies of VAECMO have also been limited because of the small sample sizes (15-202 patients) [3-14]. The Extracorporeal Life Support Organization (ELSO) Guidelines for Adult Cardiac Failure state that the estimated proportion of patients surviving to discharge after VA-ECMO for cardiogenic shock is $40 \%$ [15]. However, there are few data on the effectiveness of VA-ECMO for diseases or conditions other than cardiogenic shock. Hypothermia is the second most frequent disorder for which VA-ECMO is used, but the sample sizes of previous hypothermia studies $(\mathrm{n}=24-68)$ [16-19] were smaller than those of cardiogenic shock studies. To date, the indication for, mortality in, or successful weaning from, VA-ECMO remains unknown for diseases or conditions other than cardiogenic shock.

The aims of this study were to investigate the inhospital mortality of patients receiving VA-ECMO and the proportions of patients weaned from VA-ECMO, using data from a national inpatient database in Japan.

\section{Methods}

This study was approved by the Institutional Review Board of The University of Tokyo. The requirement for informed patient consent was waived because of the anonymous nature of the data.

\section{Data source}

The Japanese Diagnosis Procedure Combination (DPC) database includes administrative claims and discharge abstract data for all inpatients discharged from more than 1000 participating hospitals nationwide. It covers approximately $92 \%(244 / 266)$ of all tertiary-care emergency hospitals in Japan. The database includes the following patient information: age; sex; body weight and height; primary diagnosis; comorbidities on admission; post-admission complications classified according to the International Classification of Diseases 10th Revision (ICD-10) codes; medical procedures designated using original Japanese codes, including VA-ECMO, intra-aortic balloon pumping (IABP), pulmonary artery catheterization, and continuous renal replacement therapy; daily records of drug administration and devices used; length of stay; and discharge status. The dates of hospital admission, surgery, bedside procedures, drugs administered and hospital discharge are recorded using a uniform data submission form. This study used data from 1 July 2010 to 31 March 2013.

\section{Patient selection}

We included patients aged $\geq 19$ years who received VA-ECMO during hospitalization. We selected patients who were diagnosed at admission as having cardiogenic shock (ICD-10 codes, I05, I07, I08, I20-22, I33-35, I40-42, I46, and I49-51), pulmonary embolism (I26), hypothermia (T68), poisoning (T36-65), or trauma (S\$ and T0). We excluded patients with acute respiratory distress syndrome.

\section{Variables and outcomes}

Baseline variables included age, sex and body mass index (BMI). Patients with cardiogenic shock were categorized in four age groups: $19-39,40-59,60-79$ and $\geq 80$ years. BMI was categorized as being underweight (BMI $\left.<18.5 \mathrm{~kg} / \mathrm{m}^{2}\right)$, normal weight $\left(18.5-24.9 \mathrm{~kg} / \mathrm{m}^{2}\right)$, or overweight $\left(\geq 25.0 \mathrm{~kg} / \mathrm{m}^{2}\right)$. Patients were also divided into those who had or who had not had an episode of cardiac arrest. Hospital volume was defined as the number of patients receiving VA-ECMO per year at each hospital. Hospital volume was categorized in tertiles and so the number of patients in each category was almost equal. Myocarditis, chronic renal failure, liver failure, and central nervous system dysfunction were extracted based on ICD-10 codes. The primary outcome was in-hospital mortality. The secondary outcome was the proportion of patients weaned from VA-ECMO.

\section{Statistical analysis}

Data are presented as percentages and numbers, or means and standard deviations. The chi-square test and Fisher's exact test were performed to compare proportions in the different groups. In the cardiogenic shock group, we performed multivariable logistic regression analysis to examine the association of in-hospital mortality with various factors, including several components of the survival after venoarterial ECMO (SAVE) score for VA-ECMO (age, sex, weight, myocarditis (ICD-10 codes, I40-41), pre-ECMO cardiac arrest, pre-ECMO chronic renal failure (N18), liver failure pre-ECMO (K70-77), pre-ECMO central nervous system dysfunction (G09-11, G20-21, G23, G31-32, G35-37, G40-41, G45-46, G80-81, S06), and duration of intubation prior to VA-ECMO) [20], hospital volume, IABP, pulmonary artery catheterization, and continuous renal replacement therapy, while also adjusting for within-hospital clustering using a generalized estimating equation [21]. We performed multiple imputation to replace each missing value with a set of 
Table 1 Patient background $(n=5263)$

\begin{tabular}{|c|c|c|c|c|c|c|c|c|c|c|}
\hline \multirow{2}{*}{$\overline{\text { Sex }}$} & \multicolumn{2}{|c|}{ Cardiogenic shock $(n=4658)$} & \multicolumn{2}{|c|}{ Pulmonary embolism $(n=353)$} & \multicolumn{2}{|c|}{ Hypothermia $(n=99)$} & \multicolumn{2}{|c|}{ Poisoning $(n=50)$} & \multicolumn{2}{|c|}{ Trauma $(n=103)$} \\
\hline & & & & & & & & & & \\
\hline Male, $n(\%)$ & 3399 & $(73.0)$ & 131 & $(37.1)$ & 63 & $(63.6)$ & 24 & $(48.0)$ & 73 & (70.9) \\
\hline Age, mean (SD) & 64.8 & $(13.7)$ & 60.6 & $(15.6)$ & 68.7 & $(15.2)$ & 45.9 & $(18.1)$ & 56.4 & $(20.8)$ \\
\hline Death, $n$ (\%) & 3429 & (73.6) & 226 & $(64.0)$ & 65 & (65.7) & 31 & (62.0) & 66 & (64.1) \\
\hline
\end{tabular}

$S D$ standard deviation

substituted plausible values by creating 20 filled-in complete datasets using a Markov chain Monte Carlo algorithm known as "chained equations imputation," because there were some missing values for BMI and duration of intubation prior to VA-ECMO [22]. Multiple imputation assumes that data are missing at random and that any systematic differences between the missing and observed values can be explained by differences in the observed data [23]. A $p$ value $<0.05$ was considered statistically significant. All statistical analyses were performed using IBM SPSS version 22.0 (IBM Corp., Armonk, NY, USA).

\section{Results}

We identified a total of 5263 patients who received VA-ECMO during the study period. The background characteristics of the patients are presented in Table 1. The largest number of patients was in the cardiogenic shock group $(n=4658)$. The proportion of male patients in the pulmonary embolism group was smaller than that in the cardiogenic shock group. The mean age ranged from 45.9-68.7 years. In-hospital mortality ranged from $62.0-73.6 \%$.

Table 2 shows in-hospital mortality and the proportion of patients weaned from VA-ECMO in each of the five etiological categories. Overall, $34.6 \%$ of all patients died during VA-ECMO, $37.9 \%$ died after weaning from VA-ECMO, and $26.5 \%$ were discharged from hospital after weaning from ECMO.
Table 3 shows in-hospital death and the proportion of patients weaned from VA-ECMO in each of the seven underlying diseases in the cardiogenic shock group. The proportion discharged from hospital after weaning from ECMO was significantly larger in patients with heart failure $(31.1 \%, p<0.001)$ and in patients with myocarditis $(41.9 \%, p<0.001)$ than in patients with ischemic heart disease $(20.3 \%)$. The causes of death after weaning from VA-ECMO in the cardiogenic shock group were: heart failure $(n=580,30.9 \%)$; infection $(n=169,9.0 \%)$; hemorrhage ( $\mathrm{n}=135,7.2 \%)$; cerebrovascular events $(\mathrm{n}=79,4.2 \%)$; respiratory failure $(\mathrm{n}=76,4.1 \%)$; multiple organ failure ( $\mathrm{n}=248,13.2 \%)$; and other $(\mathrm{n}=211,11.3 \%)$. Data on the cause of death were missing for 377 of these patients (20.1). The types of anticoagulant used in the cardiogenic shock group were: heparin $(\mathrm{n}=3794,81.5 \%)$; dalteparin $(\mathrm{n}=32,0.7 \%)$; and argatroban $(\mathrm{n}=35,0.8 \%)$. Data were missing for 797 of these patients (17.1\%). The incidence of hemorrhage was $21.3 \%(n=808)$ with heparin, $40.6 \%(\mathrm{n}=13)$ with dalteparin, and $22.9 \%$ $(\mathrm{n}=8)$ with argatroban. Two patients also received left ventricular assistance. The numbers of patients who received VA-ECMO within $1,2,3-7$ and $\geq 8$ days of hospitalization were 2904 (62.3\%), 228 (4.9\%), 589 (12.6\%), and 937 (20.1\%), respectively.

Table 4 shows the in-hospital mortality of patients in the cardiogenic shock group, who had or had not had cardiac arrest, according to the seven underlying cardiac diseases. In-hospital mortality in patients with cardiac

Table 2 In-hospital death and weaning from VA-ECMO among patients classified by six etiological categories

\begin{tabular}{|c|c|c|c|c|c|c|c|c|c|c|c|}
\hline \multirow[b]{3}{*}{ All, $n(\%)$} & \multirow{3}{*}{$\begin{array}{l}\text { All } \\
5263\end{array}$} & \multirow{2}{*}{\multicolumn{2}{|c|}{ Total in-hospital death }} & \multirow{2}{*}{\multicolumn{2}{|c|}{$\begin{array}{l}\text { In-hospital death } \\
\text { under VA-ECMO }\end{array}$}} & \multirow{2}{*}{\multicolumn{2}{|c|}{$\begin{array}{l}\text { Transferred to } \\
\text { other hospitals } \\
\text { with VA-ECMO }\end{array}$}} & \multicolumn{4}{|c|}{ Weaning from VA-ECMO } \\
\hline & & & & & & & & \multicolumn{2}{|c|}{$\begin{array}{l}\text { Discharged after } \\
\text { weaning from VA-ECMO }\end{array}$} & \multicolumn{2}{|c|}{$\begin{array}{l}\text { In-hospital death after } \\
\text { weaning from VA-ECMO }\end{array}$} \\
\hline & & 3817 & $(72.5)$ & 1823 & (34.6) & 51 & $(1.0)$ & 1395 & $(26.5)$ & 1994 & $(37.9)$ \\
\hline Cardiogenic shock, n (\%) & 4658 & 3429 & $(73.6)$ & 1554 & $(33.4)$ & 44 & $(0.9)$ & 1185 & $(25.4)$ & 1875 & $(40.3)$ \\
\hline Pulmonary embolism, $n(\%)^{*}$ & 353 & 226 & $(64.0)$ & 151 & $(42.8)$ & 7 & $(2.0)$ & 120 & $(34.0)$ & 75 & $(21.2)$ \\
\hline Hypothermia, $n(\%)^{*}$ & 99 & 65 & $(65.7)$ & 49 & $(49.5)$ & 0 & $(0.0)$ & 34 & $(34.3)$ & 16 & $(16.2)$ \\
\hline Poisoning, $n(\%)^{* *}$ & 50 & 31 & $(62.0)$ & 22 & $(44.0)$ & 0 & $(0.0)$ & 19 & $(38.0)$ & 9 & $(18.0)$ \\
\hline Trauma, $n(\%)^{*}$ & 103 & 66 & $(64.1)$ & 47 & $(45.6)$ & 0 & $(0.0)$ & 37 & (35.9) & 19 & (18.4) \\
\hline
\end{tabular}

${ }^{*} p<0.001$ for in-hospital death after weaning from venoarterial extracorporeal membrane oxygenation (VA-ECMO) vs. cardiogenic shock

${ }^{* *} p<0.05$ for in-hospital death after weaning from VA-ECMO vs. cardiogenic shock 
Table 3 In-hospital death and weaning from VA-ECMO among patients in the cardiogenic shock group

\begin{tabular}{|c|c|c|c|c|c|c|c|c|c|c|c|}
\hline \multirow[b]{3}{*}{ Ischemic heart disease, $n$ (\%) } & \multirow{3}{*}{$\begin{array}{l}\text { All } \\
1968\end{array}$} & \multirow{2}{*}{\multicolumn{2}{|c|}{ Total in-hospital death }} & \multirow{2}{*}{\multicolumn{2}{|c|}{$\begin{array}{l}\text { In-hospital death } \\
\text { under VA-ECMO }\end{array}$}} & \multirow{2}{*}{\multicolumn{2}{|c|}{$\begin{array}{l}\text { Transferred to } \\
\text { other hospitals } \\
\text { with VA-ECMO }\end{array}$}} & \multicolumn{4}{|c|}{ Weaning from VA-ECMO } \\
\hline & & & & & & & & \multicolumn{2}{|c|}{$\begin{array}{l}\text { Discharged after } \\
\text { weaning from VA-ECMO }\end{array}$} & \multicolumn{2}{|c|}{$\begin{array}{l}\text { In-hospital death after } \\
\text { weaning from } V A-E C M O\end{array}$} \\
\hline & & 1556 & $(79.1)$ & 725 & (36.8) & 12 & (0.6) & 400 & $(20.3)$ & 831 & $(42.2)$ \\
\hline Heart failure, $n(\%)^{*}$ & 1621 & 1099 & $(67.8)$ & 488 & $(30.1)$ & 18 & $(1.1)$ & 504 & $(31.1)$ & 611 & $(37.7)$ \\
\hline Valvular disease, $n(\%)$ & 640 & 493 & $(77.0)$ & 246 & $(38.4)$ & 5 & $(0.8)$ & 142 & $(22.2)$ & 247 & (38.6) \\
\hline Myocarditis, $n(\%)^{*}$ & 186 & 106 & $(57.0)$ & 24 & $(12.9)$ & 2 & $(1.1)$ & 78 & $(41.9)$ & 82 & $(44.1)$ \\
\hline Cardiomyopathy, n (\%) & 193 & 141 & $(73.1)$ & 57 & $(29.5)$ & 6 & (3.1) & 46 & $(23.8)$ & 84 & $(43.5)$ \\
\hline Takotsubo cardiomyopathy, n (\%) & 34 & 22 & $(64.7)$ & 8 & $(23.5)$ & 0 & $(0.0)$ & 12 & (35.3) & 14 & $(41.2)$ \\
\hline Infectious endocarditis, n (\%) & 16 & 12 & (75.0) & 6 & (37.5) & 1 & (6.3) & 3 & (18.8) & 6 & (37.5) \\
\hline
\end{tabular}

${ }^{*} p<0.001$ for in-hospital death after weaning from venoarterial extracorporeal membrane oxygenation (VA-ECMO) vs. ischemic heart disease

arrest ranged from $60.9-100 \%$ and in patients without cardiac arrest it ranged from $54.9 \%-77.0 \%(p<0.001)$. In-hospital mortality was significantly lower in patients who had not had cardiac arrest than in those who had had cardiac arrest for those with cardiogenic shock, heart failure and cardiomyopathy $(70.5 \%$ vs. $77.1 \%$, $p<0.001 ; 64.9 \%$ vs. $71.7 \%, p<0.05$; and $61.0 \%$ vs. $81.0 \%, p<0.05$, respectively).

Table 5 presents the in-hospital mortality in each category of patients undergoing VA-ECMO for cardiogenic shock. Sex was not significantly associated with mortality. No significant differences in in-hospital mortality were observed between the hospital volume categories.

Table 6 shows the results of the multivariable logistic regression analysis for in-hospital mortality, including multiple imputation. Higher age, and greater or smaller BMI were significantly associated with higher mortality. Hospital volume was not significantly associated with mortality.

\section{Discussion}

The present study investigated the indication for, mortality in, and rate of successful weaning from VA-ECMO, using a Japanese national DPC inpatient database. The majority of patients receiving VA-ECMO had cardiogenic shock (88.5\%). In-hospital mortality was about $65 \%$ for all underlying diseases, and the rate of weaning from VA-ECMO was about $65 \%$. The advantage of this study was its much larger sample size than was used in previous studies. The present study clarified the practice patterns in the use of VA-ECMO in a nationwide clinical setting. Although there is no evidence on the effectiveness of VA-ECMO for trauma patients, our results showed that VA-ECMO was used for some trauma patients in real-world clinical practice. The present study demonstrated significantly lower mortality in the trauma group compared with the cardiogenic shock group. This may be because patients in the trauma group were relatively younger and had fewer chronic diseases.

In this study we observed the in-hospital mortality under VA-ECMO and weaning from VA-ECMO according to each disease or condition. Mortality during VAECMO was $34.6 \%$, the overall rate of discharge was about $30 \%$, and in-hospital mortality after weaning from VA-ECMO was about $40 \%$. About half of patients weaned from VA-ECMO died in hospital. This high proportion may be partly explained by the persisting severe condition of the patients after weaning from VA-ECMO.

Table 4 In-hospital mortality among patients in the cardiogenic shock group, who had or had not had cardiac arrest

\begin{tabular}{|c|c|c|c|c|c|c|}
\hline \multirow[b]{2}{*}{ All, $n(\%)^{*}$} & \multirow{2}{*}{$\begin{array}{l}\text { Patients who had not } \\
\text { had cardiac arrest } \\
2471\end{array}$} & \multicolumn{2}{|c|}{$\begin{array}{l}\text { Deaths among patients who } \\
\text { had not had cardiac arrest }\end{array}$} & \multirow{2}{*}{$\begin{array}{l}\text { Patients who had } \\
\text { had cardiac arrest } \\
2187\end{array}$} & \multicolumn{2}{|c|}{$\begin{array}{l}\text { Deaths among patients who } \\
\text { had had cardiac arrest }\end{array}$} \\
\hline & & 1742 & $(70.5)$ & & 1687 & $(77.1)$ \\
\hline Ischemic heart disease, $n(\%)$ & 803 & 618 & $(77.0)$ & 1165 & 938 & $(80.5)$ \\
\hline Heart failure, $n(\%)^{* *}$ & 922 & 598 & $(64.9)$ & 699 & 501 & $(71.7)$ \\
\hline Valvular disease, $n(\%)$ & 515 & 391 & $(75.9)$ & 125 & 102 & $(81.6)$ \\
\hline Myocarditis, n (\%) & 122 & 67 & $(54.9)$ & 64 & 39 & $(60.9)$ \\
\hline Cardiomyopathy, $n(\%)^{* *}$ & 77 & 47 & $(61.0)$ & 116 & 94 & $(81.0)$ \\
\hline Takotsubo cardiomyopathy, n (\%) & 19 & 12 & $(63.2)$ & 15 & 10 & $(66.7)$ \\
\hline Infectious endocarditis, $n$ (\%) & 13 & 9 & $(69.2)$ & 3 & 3 & $(100.0)$ \\
\hline
\end{tabular}

${ }^{*} p<0.001$ for mortality among patients who had not had vs. those who had had cardiac arrest

${ }^{* *} p<0.05$ for mortality among patients who had not had vs. those who had had cardiac arrest 
Table $\mathbf{5}$ In-hospital mortality in patients undergoing VA-ECMO for cardiogenic shock

\begin{tabular}{|c|c|c|c|c|}
\hline & Patients, $n$ & Deaths & $5, n(\%)$ & $P$ value \\
\hline Total & 4658 & 3429 & $(73.6)$ & \\
\hline Age, years & & & & $<0.001$ \\
\hline 19-39 & 271 & 170 & $(62.7)$ & \\
\hline $40-59$ & 1079 & 738 & $(68.4)$ & \\
\hline $60-79$ & 2741 & 2058 & $(75.1)$ & \\
\hline$\geq 80$ & 567 & 463 & $(81.7)$ & \\
\hline Sex & & & & 0.775 \\
\hline Male & 3399 & 2506 & $(73.7)$ & \\
\hline Female & 1259 & 923 & (73.3) & \\
\hline Hospital volume per year & & & & 0.071 \\
\hline $0-9$ & 1671 & 1263 & $(75.6)$ & \\
\hline 10-19 & 1554 & 1123 & $(72.3)$ & \\
\hline$\geq 20$ & 1433 & 1043 & $(72.8)$ & \\
\hline Body mass index, $\mathrm{kg} / \mathrm{m}^{2}$ & & & & $<0.001$ \\
\hline$<18.5$ & 406 & 295 & $(72.7)$ & \\
\hline $18.5-24.9$ & 2223 & 1521 & $(68.4)$ & \\
\hline$\geq 25.0$ & 1085 & 772 & $(71.2)$ & \\
\hline Missing & 944 & 841 & $(89.1)$ & \\
\hline Etiology & & & & $<0.001$ \\
\hline Ischemic heart disease & 1968 & 1556 & $(79.1)$ & \\
\hline Heart failure & 1621 & 1099 & $(67.8)$ & \\
\hline Valvular disease & 640 & 493 & $(77.0)$ & \\
\hline Myocarditis & 186 & 106 & $(57.0)$ & \\
\hline Cardiomyopathy & 193 & 141 & $(73.1)$ & \\
\hline Takotsubo cardiomyopathy & 34 & 22 & $(64.7)$ & \\
\hline Infectious endocarditis & 16 & 12 & $(75.0)$ & \\
\hline Cardiac arrest & & & & $<0.001$ \\
\hline No & 2471 & 1742 & $(70.5)$ & \\
\hline Yes & 2187 & 1687 & $(77.1)$ & \\
\hline Chronic renal failure & & & & 0.464 \\
\hline No & 4139 & 3040 & $(73.4)$ & \\
\hline Yes & 519 & 389 & $(75.0)$ & \\
\hline Liver failure & & & & 0.974 \\
\hline No & 4594 & 3382 & $(73.6)$ & \\
\hline Yes & 64 & 47 & $(73.4)$ & \\
\hline Central nervous system dysfunction & & & & 0.527 \\
\hline No & 4605 & 3392 & $(73.7)$ & \\
\hline Yes & 53 & 37 & $(69.8)$ & \\
\hline $\begin{array}{l}\text { Duration of intubation prior } \\
\text { to } V A-E C M O \text {, days }\end{array}$ & & & & $<0.001$ \\
\hline 0 & 2576 & 2007 & (77.9) & \\
\hline 1 & 33 & 23 & $(69.7)$ & \\
\hline$\geq 2$ & 115 & 66 & (57.4) & \\
\hline
\end{tabular}

Table 5 In-hospital mortality in patients undergoing VA-ECMO for cardiogenic shock (Continued)

\begin{tabular}{lcccc}
\hline Missing & 1934 & 1333 & $(68.9)$ & \\
Use of intra-aortic balloon pumping & & & & $<0.001$ \\
No & 1828 & 1438 & $(78.7)$ & \\
Yes & 2830 & 1991 & $(70.4)$ & \\
Use of continuous renal replacement therapy & & & $<0.001$ \\
No & 2893 & 2058 & $(71.1)$ & \\
Yes & 1765 & 1371 & $(77.7)$ & \\
\hline VA-ECMO venoarterial extracorporeal membrane oxygenation &
\end{tabular}

Furthermore, for some patients weaned from VAECMO, further treatment may have been discontinued because of their unfavorable brain condition.

In the cardiogenic shock group, the proportion of inhospital deaths under VA-ECMO was smaller than that after weaning from VA-ECMO, in contrast with the other groups. This finding may suggest that patients with cardiogenic shock were more likely to have brain damage than other groups of patients, resulting in a lower survival rate. Only two patients received implantation of a left ventricular assistance device. Implantation of a left ventricular assistance device has only been approved as a bridge to transplantation since 2011. However, switching from VA-ECMO to a left ventricular assistance device is not popular, because of the severe shortage of cardiac donors in Japan [24].

In-hospital mortality was lower in patients who had not had cardiac arrest than in those who had had cardiac arrest. This finding indicates that cardiac arrest may also be a predictor of VA-ECMO outcome.

In-hospital mortality was higher in older patients and in patients with high or low BMI. This indicates that successful outcomes for VA-ECMO in the cardiogenic group were associated with younger age and appropriate BMI. This finding could suggest that age and BMI are predictors of VA-ECMO outcome. Hospital volume was not significantly associated with in-hospital mortality. High-volume hospitals may treat severely ill patients on VA-ECMO more than low-volume hospitals because of differences in the criteria for implementing VA-ECMO. Use of IABP was associated with lower mortality. It is recognized that VA-ECMO increases cardiac afterload due to its reversed vascular flow. Consequently, VA-ECMO reduces cardiac output and causes left ventricular distension [25]. As IABP reduces afterload and increases coronary blood flow [26], it may have reduced mortality by increasing cardiac output and decompressing the left ventricle.

There are some limitations in this study. This study was retrospective and was based on data from an administrative database, which did not include complete data on physiology, severity of illness, the patient's physical condition, or duration of time between cardiac arrest 
Table 6 Multivariable logistic regression with multiple imputation for analysis of in-hospital mortality in patients undergoing VA-ECMO for cardiogenic shock

\begin{tabular}{lll}
\hline Odds ratio & $95 \%$ & $P$ value \\
& $\begin{array}{l}\text { Confidence } \\
\text { interval }\end{array}$ \\
\hline
\end{tabular}

Age, years
$19-39$
$40-59$
$60-79$
$\geq 80$
Sex
Male
Female
Hospital volume per year
$0-9$
$10-19$
$\geq 20$

Body mass index, $\mathrm{kg} / \mathrm{m}^{2}$

$<18.5$
$18.5-24.9$
$\geq 25.0$
Etiology
Ischemic heart disease
Heart failure
Valvular disease
Myocarditis
Cardiomyopathy
Takotsubo cardiomyopathy
Infectious endocarditis
Cardiac arrest
No
Yes

Chronic renal failure

$$
\begin{aligned}
& \text { No } \\
& \text { Yes }
\end{aligned}
$$

Liver failure pre-ECMO

$$
\begin{aligned}
& \text { No } \\
& \text { Yes }
\end{aligned}
$$

Central nervous system dysfunction pre-ECMO

$$
\begin{aligned}
& \text { No } \\
& \text { Yes }
\end{aligned}
$$

Duration of intubation prior to $\mathrm{VA-ECMO}$, days

$$
\begin{gathered}
0 \\
1 \\
\geq 2
\end{gathered}
$$

$\begin{array}{llll}\text { Reference } & & & \\ 1.08 & 0.79 & 1.47 & 0.65 \\ 1.64 & 1.23 & 2.17 & 0.001 \\ 2.61 & 1.81 & 3.77 & <0.001\end{array}$

Reference

$\begin{array}{llll}0.96 & 0.82 & 1.12 & 0.61\end{array}$

Reference

$\begin{array}{llll}0.83 & 0.68 & 1.01 & 0.07\end{array}$

$\begin{array}{llll}0.80 & 0.63 & 1.02 & 0.07\end{array}$

$\begin{array}{llll}1.28 & 1.01 & 1.62 & 0.04\end{array}$

Reference

$\begin{array}{llll}1.24 & 1.04 & 1.47 & 0.02\end{array}$

Reference

$\begin{array}{llll}0.55 & 0.46 & 0.65 & <0.001\end{array}$

$\begin{array}{lllll}0.85 & 0.66 & 1.10 & 0.22\end{array}$

$\begin{array}{lllll}0.42 & 0.31 & 0.57 & <0.001\end{array}$

$\begin{array}{llll}0.75 & 0.51 & 1.08 & 0.12\end{array}$

$\begin{array}{llll}0.58 & 0.27 & 1.21 & 0.14\end{array}$

$\begin{array}{llll}0.69 & 0.21 & 2.28 & 0.55\end{array}$

Reference

$\begin{array}{llll}1.52 & 1.28 & 1.82 & <0.001\end{array}$

Reference

$\begin{array}{llll}0.90 & 0.69 & 1.16 & 0.40\end{array}$

$\begin{array}{llll}1.30 & 0.71 \quad 2.38 & 0.40\end{array}$

Reference

$\begin{array}{llll}0.87 & 0.45 & 1.70 & 0.68\end{array}$

Reference

$\begin{array}{llll}1.03 & 0.44 & 2.39 & 0.94\end{array}$

$\begin{array}{llll}0.47 & 0.32 & 0.70 & <0.001\end{array}$
Reference
Table 6 Multivariable logistic regression with multiple imputation for analysis of in-hospital mortality in patients undergoing VA-ECMO for cardiogenic shock (Continued)

\begin{tabular}{lllll}
\hline Use of intra-aortic balloon pumping & & & & \\
No & Reference & & & \\
Yes & 0.58 & 0.49 & 0.68 & $<0.001$ \\
Use of continuous renal replacement & & & & \\
therapy & & & & \\
No & Reference & & \\
Yes & 1.95 & 1.63 & 2.33 & $<0.001$ \\
\hline VA-ECMO venoarterial extracorporeal membrane oxygenation & &
\end{tabular}

and initiation of VA-ECMO. Generally, in retrospective observational studies using administrative data, recorded diagnoses are less well-validated than those in planned prospective surveys. Severe organ dysfunction may have been more likely to be recorded than mild-to-moderate dysfunction. The lack of a control group precluded any conclusion as to whether there was an association between use of VA-ECMO and mortality. Because of the way that data were recorded, we were also not able to differentiate patients who were in cardiac arrest before ECMO was initiated from those in whom ECMO was established for ongoing cardiac arrest during cardiopulmonary resuscitation.

\section{Conclusions}

This study was based on data from a nationwide database in Japan to determine mortality rates in patients who received VA-ECMO. Mortality rates were high, especially in patients with cardiogenic shock and in patients who had cardiac arrest. Weaning from VA-ECMO did not necessarily result in survival. The present study provides information about the current status of VA-ECMO use in Japan; further studies are needed to investigate the effects of VA-ECMO.

\section{Key messages}

- In-hospital mortality was $72.5 \%$ in 5263 patients receiving VA-ECMO

- More than $50 \%$ of patients weaned from VA-ECMO died in hospital

- Age, BMI and cardiac arrest were predictors of mortality after VA-ECMO

\section{Abbreviations}

BMl: body mass index; DPC: Diagnosis Procedure Combination; IABP: intra-aortic balloon pumping; ICD-10: International Classification of Diseases 10th Revision;

VA-ECMO: venoarterial extracorporeal membrane oxygenation.

Competing interests

The authors declare that they have no competing interests. 


\section{Authors' contributions}

$\mathrm{SA}, \mathrm{HM}$, and $\mathrm{HY}$ performed the statistical analyses and produced the first draft of the manuscript. KF contributed to the study design and data acquisition. All authors commented on the manuscript, and approved the final version.

\section{Acknowledgements}

$\mathrm{HY}$ and KF received grant support from the Japanese government. This work was supported by grants for Research on Policy Planning and Evaluation from the Ministry of Health, Labour and Welfare, Japan (grant numbers: H27-Policy-Designated-009 and H27-Policy-Strategy-011). The funders had no role in the execution of this study or interpretation of the results.

\section{Author details}

'Department of Clinical Epidemiology and Health Economics, School of Public Health, The University of Tokyo, 7-3-1 Hongo, Bunkyo-ku, Tokyo 113-0033, Japan. ${ }^{2}$ Department of Health Policy and Informatics, Tokyo Medical and Dental University Graduate School of Medicine, 1-5-45 Yushima, Bunkyo-ku, Tokyo 113-8510, Japan

Received: 12 July 2015 Accepted: 8 March 2016

\section{Published online: 05 April 2016}

\section{References}

1. Ventetuolo CE, Muratore CS. Extracorporeal life support in critically ill adults. Am J Respir Crit Care Med. 2014;190:497-508.

2. Kurose M, Okamoto K, Sato T, Ogata K, Yasumoto M, Terasaki H, et al. Extracorporeal life support for patients undergoing prolonged externa cardiac massage. Resuscitation. 1993;25:35-40.

3. Wu M-Y, Tseng Y-H, Chang Y-S, Tsai F-C, Lin P-J. Using extracorporeal membrane oxygenation to rescue acute myocardial infarction with cardiopulmonary collapse: the impact of early coronary revascularization. Resuscitation. 2013;84:940-5.

4. Tang GHL, Malekan R, Kai M, Lansman SL, Spielvogel D. Peripheral venoarterial extracorporeal membrane oxygenation improves survival in myocardial infarction with cardiogenic shock. J Thorac Cardiovasc Surg. 2013;145:e32-3.

5. Takayama H, Truby L, Koekort M, Uriel N, Colombo P, Mancini DM, et al. Clinical outcome of mechanical circulatory support for refractory cardiogenic shock in the current era. J Heart Lung Transplant. 2013;32:106-11.

6. Smedira NG, Moazami N, Golding CM, McCarthy PM, Apperson-Hansen C, Blackstone EH, et al. Clinical experience with 202 adults receiving extracorporeal membrane oxygenation for cardiac failure: survival at five years. J Thorac Cardiovasc Surg. 2001;122:92-102.

7. Magovern GJ, Simpson KA. Extracorporeal membrane oxygenation for adult cardiac support: the Allegheny experience. Ann Thorac Surg. 1999;68:655-61.

8. Combes A, Leprince P, Luyt C-E, Bonnet N, Trouillet J-L, Leger P, et al. Outcomes and long-term quality-of-life of patients supported by extracorporeal membrane oxygenation for refractory cardiogenic shock. Crit Care Med. 2008:36:1404-11.

9. Chung S-Y, Sheu J-J, Lin Y-J, Sun C-K, Chang L-T, Chen Y-L, et al. Outcome of patients with profound cardiogenic shock after cardiopulmonary resuscitation and prompt extracorporeal membrane oxygenation support. Circ J. 2012:76:1385-92.

10. Chen J-S, Ko W-J, Yu H-Y, Lai L-P, Huang S-C, Chi N-H, et al. Analysis of the outcome for patients experiencing myocardial infarction and cardiopulmonary resuscitation refractory to conventional therapies necessitating extracorporeal life support rescue. Crit Care Med. 2006;34:950-7.

11. Beurtheret S, Mordant P, Paoletti X, Marijon E, Celermajer DS, Leger P, et al. Emergency circulatory support in refractory cardiogenic shock patients in remote institutions: a pilot study (the cardiac-RESCUE program). Eur Heart J. 2013:34:112-20.

12. Hsu K-H, Chi N-H, Yu H-Y, Wang C-H, Huang S-C, Wang S-S, et al. Extracorporeal membranous oxygenation support for acute fulminant myocarditis: analysis of a single center's experience. Eur J Cardiothorac Surg. 2011;40:682-8.

13. Chen $Y-S$, Yu H-Y, Huang S-C, Chiu K-M, Lin T-Y, Lai L-P, et al. Experience and result of extracorporeal membrane oxygenation in treating fulminant myocarditis with shock: what mechanical support should be considered first? J Heart Lung Transplant. 2005;24:81-7.

14. Asaumi Y, Yasuda S, Morii I, Kakuchi H, Otsuka Y, Kawamura A, et al. Favourable clinical outcome in patients with cardiogenic shock due to fulminant myocarditis supported by percutaneous extracorporeal membrane oxygenation. Eur Heart J. 2005;26:2185-92.
15. Extracorporeal Life Support Organization. ELSO guidelines for adult cardiac failure v1.3. Michigan, USA, 2015. http://www.elso.org/Resources/Guidelines. aspx. Accessed 1 July 2015

16. Walpoth BH, Walpoth-Aslan BN, Mattle HP, Radanov BP, Schoroth G, Schaeffler $L$, et al. Outcome of survivors of accidental deep hypothermia and circulatory arrest treated with extracorporeal blood warming. N Engl J Med. 1997;337(21):1500-5

17. Ruttmann E, Weissenbacher A, Ulmer H, Muller L, Hofer D, Kilo J, et al. Prolonged extracorporeal membrane oxygenation-assisted support provides improved survival in hypothermic patients with cardiocirculatory arrest. J Thorac Cardiovasc Surg. 2007:134:594-600.

18. Morita S, Inokuchi S, Yamagiwa T, lizuka S, Yamamoto R, Aoki H, et al. Efficacy of portable and percutaneous cardiopulmonary bypass rewarming versus that of conventional internal rewarming for patients with accidental deep hypothermia. Crit Care Med. 2011:39:5-9.

19. Farstad M, Andersen KS, Koller M-E, Grong K, Segadal L, Husby P. Rewarming from accidental hypothermia by extracorporeal circulation. A retrospective study. Eur J Cardiothorac Surg. 2001;20:58-64.

20. Schmidt M, Burrell A, Roberts L, Bailey M, Sheldrake J, Rycus PT, et al. Predicting survival after ECMO for refractory cardiogenic shock: the survival after veno-arterial-ECMO (SAVE)-score. Eur Heart J. 2015;36:2246-56.

21. Hubbard AE, Ahern J, Fleischer NL, Van der Laan M, Lippman SA, Jewell N, et al. To GEE or not to GEE: comparing population average and mixed models for estimating the associations between neighborhood risk factors and health. Epidemiology. 2010;21:467-74.

22. Rubin DB, Schenker N. Multiple imputation in health-care databases: an overview and some applications. Stat Med. 1991;10:585-98.

23. Sterne JAC, White IR, Carlin JB, Spratt M, Royston P, Kenward MG, et al. Multiple imputation for missing data in epidemiological and clinical research: potential and pitfalls. BMJ. 2009;338:b2393.

24. Higo T. A classical but useful predictor of future left ventricular assist device explantation. Circ J. 2015;79:505-7.

25. Rupprecht L, Flörchinger B, Schopka S, Schmid C, Philipp A, Lunz D, et al. Cardiac decompression on extracorporeal life support: a review and discussion of the literature. ASAIO J. 2013:59:547-53.

26. Kern M, Aguirre F, Tatineni S, Penick D, Serota H, Donohue T, et al. Enhanced coronary blood flow velocity during intraaortic balloon counterpulsation in critically ill patients. J Am Coll Cardiol. 1993;21:359-68.

\section{Submit your next manuscript to BioMed Central and we will help you at every step:}

- We accept pre-submission inquiries

- Our selector tool helps you to find the most relevant journal

- We provide round the clock customer support

- Convenient online submission

- Thorough peer review

- Inclusion in PubMed and all major indexing services

- Maximum visibility for your research

Submit your manuscript at www.biomedcentral.com/submit
Biomed Central 